\title{
The Struggle for Control: How do Norwegian TV-Celebrities Deal With Critical Media Exposure?
}

\author{
Fanny Duckert ${ }^{1}$, Kim Edgar Karlsen ${ }^{2}$ \\ ${ }^{1}$ Department of Psychology, University of Oslo, Norway \\ ${ }^{2}$ Diakonhjemmet Hospital, Norway \\ Correspondence: Fanny Duckert, Department of Psychology, University of Oslo, Norway.
}

Received: May 15, 2019

doi:10.11114/smc.v7i2.4608
Online Published: November 6, 2019

URL: https://doi.org/10.11114/smc.v7i2.4608

\begin{abstract}
Ten Norwegian TV-hosts, all nation-wide celebrities, were interviewed about their experiences with critical media exposure. How did they perceive their relationship with the press? What were the main sources of stress? How did they cope?

All expressed a strong focus on impression management and self-presentation. The majority described an independent and often playful interaction with the press, in order to keep control over their programs and their privacy.

All had experienced negative media exposure. Sources of stress were one-sided presentations, evil informers, personal attacks, and harming their family. They experienced both direct effects by the media coverage, and indirect effects through interaction with other people.

The majority used problem-focused coping strategies, actively influencing the media coverage; emotion-focused strategies, regulating their thoughts and feelings; and meaning-focused strategies, allowing reflection. Proactive self-presentation work helped maintain and protect their identities.
\end{abstract}

Two of the participants reported using more defensive strategies, and had suffered more intensely.

Keywords: TV-celebrities, media exposure, stress, coping strategies, impression management, self-presentation

\section{Introduction}

The term celebrity defines a person whose name, image, lifestyle, and opinions carry cultural and economic worth, and who are primary idealized popular media constructions (Redmond, 2014). Celebrities exist in the eye of media, are often adored by their fans, and are valuable commodities in terms of their use and exchange value.

Television personalities is a certain sub group of celebrities. They are famous for being famous, and are famous only as far as they make frequent television appearances. The television identity is a relatively stable identity that emerges in and between the flow of programming and genre segmentation. In contrast to for instance film stars, the television personalities are ordinary and attainable, and go by their real names in authentic and realistic environments. They tie their self-presentations to their ordinariness, built on stability, familiarity and a high degree of intimacy. Television personalities employ direct address, or are tied to programs where their, often ordinary, characters shine.

People are agents who actively construct, maintain, and protect their social environments (Schlenker \& Pontari, 2000). People's abilities to influence others and navigate their social worlds effectively are regarded as vital components of social intelligence. People attempt to control the images they project, and try to present themselves favorably. Self-presentation agendas involve constructing, maintaining and protecting desired images of self. Individuals try to influence others and arrange events as to produce more beneficial, less threatening surroundings. They may package information in nearly unlimited ways to make desired points. Much self-presentation activities are guided by automatic processes, seem perfectly natural to the actor and audience, and therefore goes unnoticed.

When the audience or situation becomes problematic, self-presentation shifts to the foreground, as people become conscious of the impressions they are making, and exert cognitive effort to plan, monitor, and control their actions. Celebrities will usually be high on self-monitoring and public self-consciousness, and deliberately self-present across a variety of situations (Buss and Briggs, 1984). 
The public self-presentation of celebrities is aimed at maintaining or increasing the perception of their personalities as being attractive and likeable (Schütz, 1997). Their chief asset is their personality, and the audience wants to learn about their private lives. To be popular and to create a feeling of intimacy between themselves and their audiences, entertainers often let the public know how they live and how they feel. Typical is to provide personal information such as talking about their marital and family relations, friendships, ideals and feelings. Thus, self-disclosure becomes a tool for strengthening the relationship between the celebrities and their audiences. On the other hand, of special importance is to protect their impression on others and to control their self-presentations.

Celebrity life brings benefits, but also costs as loss of privacy, invasion of strangers who want attention - and always having to play a special role when in public. The loss of privacy is the most obviously unwelcome trapping of fame. Not only fans, but also the media themselves are tracking the celebrities' every move. Therefore, there is an acute sense of living in a goldfish bowl, constantly under observation. Movement becomes restricted, as the celebrities often need to be chaperoned for their own protection.

The interest from media is a special part of fame. The media and the celebrities are in a symbiotic relationship. The celebrities are part of the news input of the media, and at the same time need the attention the media represent. This is in itself a challenge. Even the earthiest stars know the pressure of being in the spotlight of the media all the time. It is demanding to be acknowledged and respected as individuals in a media world filled with stereotypes. Insulation and loneliness can be a long-term price to pay.

Keeping up the facade is essential for maintaining the image that one has meticulously built up. The demand for the perfect facade means that one must suppress anger, sadness or fear that negative or overwhelming critical pressure may imply (Rockwell and Giles 2009).

Those who accept their debt to the media probably cope better with fame than those who see media as simply providing a window through others can admire their brilliance (Giles 2010).

Kepplinger (2007), has introduced the term reciprocal effect, referring to the ways in which subjects of media stories are influenced by the media coverage both directly, through encounters with journalists and news reports, and indirectly, through interaction with people in their environment. Through a so-called looking-glass process, the exposed individuals form ideas about other people's attitudes toward them, often based on the content of the media coverage and perceived changes in others' behavior. Kepplinger has demonstrated that high levels of anger and feelings of helplessness towards the media are common among both media experienced and inexperienced individuals. This challenges the common assumption that experienced actors are less susceptible to the effects of negative media exposure.

How do the celebrities cope with media induced stress? Transactional models of stress emphasize the ongoing interaction between the person and the environment. The outcome of a stressful event depends on the individual's use of adaptive coping strategies (Lazarus, 2006). Lazarus has differentiated between so-called problem-solving strategies, aimed at changing stressful aspects of the situation, and emotion-focused strategies, which regulate thoughts, feelings and mental states. A third category is meaning-focused strategies, referring to the effort at making sense of the situation.

In our study, we have wished to collect more information about how TV celebrities perceive their relationship with media, and how they deal with critical press coverage. How are their reflections about their own situation and role? What are the reciprocal effects of critical media exposure? What kind of strategies and conscious techniques do they use in order to try to protect themselves from media related stress?

\section{Methods}

We have interviewed ten professional media personalities. Our participants (seven male and three female), were all nation-wide celebrities, 30-55 years of age, and working as TV hosts at the time of the interview. The Norwegian Broadcast Company (NRK), which is the state owned broadcast company, employed them all. They worked in different channels with a variety of TV shows (i.e. Friday/Saturday night talk shows, humor/satirical shows, and debate programs). Six had stable positions, and four were on temporary contracts.

Several elements made them interesting to us: They were individuals who received a lot of media attention because of their professional practice on television - and because of their status as celebrities. They had varied media experiences and usually worked close to journalists. They had actively sought the media attention and were motivated to remain in the spotlight, unlike people who are exposed in media because of isolated events. They were competent and seasoned in their professional roles, and willing to share their personal reflections with us. 


\section{Research questions:}

How do you perceive your media role and your relationship to journalists?

Have you experienced negative feedback from media?

What was especially stressful?

What were the implications for your work and life situation?

What did you do for dealing with the situation and the resulting stress?

How do you protect yourself in public?

\section{Interviews and analytic procedure}

The study was qualitative and explorative. We used a semi structured interview guide with open-ended questions, followed by more specific questioning about the participants' thoughts, feelings, and ways of coping.

Our aim was to assess their subjective experiences of psychological strain and their coping strategies. To remain close to the individuals' own experiences and stories, we did not interview outside journalists or include other media perspectives in our analyses, nor did we evaluate the correctness or fairness of the media coverage.

The interviews usually lasted about two hours, and were tape-recorded. Afterwards, we transcribed the interviews verbatim, and analyzed the data according to the protocol for consensual qualitative research (CQR) (Hill and Thompson 1997, Hill, Knox et al. 2005). CQR is ideal for conducting in-depth studies of the inner experiences of individuals. As part of the process, we organized a research group consisting of the researchers (psychologists), and the research assistants (psychology students). First, we conducted individual thematic analysis (Braun and Clarke, 2006). The researchers listened to the tapes and made individual analyses of the transcribed manuscripts, before meeting in the group to discuss the interpretations. We analyzed the interviews in a step-vise process moving from developing and coding domains, constructing core ideas, and developing categories to describe consistencies across cases (cross-analysis).

\section{Ethical issues}

All participants received information about the project and procedures, and about the option to withdraw at any time, and all signed a written consent form. The Regional Ethics Committee has approved the study. We anonymized the participants in order to ensure confidentiality. However, four of the participants did not wish to remain anonymous and allowed identification in the results. The participants have read and approved their contributions before publication.

\section{Results}

\section{The TV personalities' relationship to the press}

As a group, the TV hosts experienced themselves as competent and equal or superior to ordinary journalists. They described active impression management strategies (Schlenker and Pontari, 2000), and demonstrated a high consciousness about how to conduct their self-presentations.

The majority described an independent and often playful interaction with the media. They were also conscious of the competition with journalists about who should define and control the interview situations, and what kind of information they should give out. An important goal was to protect their personal image, and keep control over their programs, themselves and their private lives. One of the senior talk show hosts stated: "I am originally a journalist myself. I am a professional storyteller and a competitor in telling my own stories". They described this as an ongoing struggle: "Early on, I discovered when interacting with journalists that they did a sloppy job. I realized that it was a hopeless task to make things right, so I decided to just fool around with them, alternating between seriousness and joking".

The host of a critical series, questioning researchers in Social Sciences, described how he and his team had used multiple tactics to create effects that could promote their program: "We tried to get a first page in one of the newspapers with the headline that I was racist. Because then, people would see the program afterwards and say: 'But this is not racist'. In this way we received more attention and sympathy than if we just had said: 'there are some intelligence differences on human groups here'. This strategy worked out quite well".

Not everybody in the group had the same approach. Three of the subjects stressed that they perceived themselves as responsible and decent with an open and honest relationship with the press. They perceived themselves as professional journalists and expected to be taken seriously by the media. Integrity and accountability were important ideals to them.

\section{The experience of negative press exposure}

All the TV hosts had experienced negative media exposure. The contents, intensity and duration of the coverage varied. Some of the entries were triggered by their professional roles and incidents in their TV-shows, while others were caused 
by episodes in their private lives that had caught the interest of the media (for instance personal problems or private scandals). Most felt this as stressful and unpleasant. However, several pointed out that being a celebrity and occupying a public role, one had to tolerate critical exposure without feeling offended. Most of the time such coverage would be short lived and disappear without serious consequences: "It's just a bit of a gossip. It is just somewhat disgusting, as if someone is talking about you behind you back, or thinking something that you do not control yourself."

The most acclaimed celebrity in the group, hosting a prime-time talk show, had experienced that several of his shows were severely criticized, for instance, for being sexist, too rude or for bullying sick people. However, he emphasized that he had voluntarily chosen his advanced public role, and had to be able to tolerate more pressure without becoming self-defensive. In periods, there could be a lot of noise but this was usually temporally.

Some even mentioned that negative media attention sometimes even could have positive effects, either because of giving ideas for new shows, or because they found it stimulating and fun to deal with.

\section{Sources of stress}

\section{The press coverage}

All the TV personalities described mistakes, wrong facts and skewedness in the media presentations. Everyone spoke of errors in the content, and that the press reports were not professional and neutral but subjectively and commercially angled. They experienced that the journalists had an evil agenda, or worked fraudulently with the intention of making a scandal. The press used quotations taken out of context, one-source journalism, and breach of agreements in order to achieve special angles in the presentation. Facts were wrong, the framing ill-natured and biased. As a result, they often experienced loss of control and disqualification.

\section{Lack of control}

A major problem was the lack of influence in the process. They felt that they were exploited and under-estimated by the journalists. An important part of their frustration was that as TV hosts they were dependent on media as a communication channel with their audience, and felt a strong need for control in that relationship.

\section{The journalists' use of sources and informants}

A special issue was the journalists' use of sources. As celebrities, the TV hosts often experienced that outsiders used them as stepping-stones for media attention: "They will easily find someone who is aggressive and who would love to criticize me in public in order to get an attention he otherwise would never have." They called for more ethical awareness, and that the journalists should be more alert about potential sources' underlying motifs and interests.

\section{Negative advances from strangers}

Particular of our group of participants was the high incidence of negative advances from strangers. More than half of the TV hosts had received threats, hate letters and malicious messages on social media. They perceived such experiences as a serious cost to their professional role.

This was in line with the information from the management of NRK that many of their employees were stalked, received unwanted sexual letters or got slick feedback. NRK considered this as a serious problem, and had over time built their own safety practices to protect employees:

"Traditionally, the most common threat or threatening situation for NRK employees is something that largely affects projected program hosts, usually women - and it is linked to unwanted sexual awareness or unwanted close attention from outsiders. Visibility can be seen in conjunction with objectification. - The person is perceived as an object - not a person but a thing for others to look at, use or consume" (Program Director in NRK, in Hagen, 2015).

\section{Workplace challenges}

Several of the TV hosts described worries and challenges in relation to their workplace conditions, caused by the negative media exposure. This included concern about career loss and betrayal, or lack of support from management and coworkers. Such topics were consistent in almost all our cases. For some, the negative media focus happened at a vulnerable time in their career: "You become very self-critical and vulnerable, and you are so dependent on the fact that they like you for giving you jobs. So, that's the stress, almost to be discovered as unworthy."

"It was a breakdown of my work situation; I was taken off the program, no more engagements."

More than half of the group stated that they missed support from management and / or colleagues during the critical media exposure. The participants especially missed support from their own editorial staff: "I felt alone. We were a team when we made the program, but I had to get up and take the criticism alone." 
Special for our participants was that they had attractive jobs that were interesting and exciting for family and friends. Everyone noticed reactions from their social environment when criticized. People around could experience the situation as more glamorous and less stressful than the program host him/herself: "They thought this was fabulous! I think they never realized how unpleasant it was to be me in this situation." In addition, people began to behave differently. Several felt that the interest of others became straining because it made them aware of the scope of the exposure, and they were continuously reminded about the situation: "We have a kind of agreement not to talk about me. Nevertheless, they always comment on what to do, and not to do in relation to my situation. I'm trying to avoid the attention but they will always talk about me and what has happened to me."

On the other hand, their social connections could believe in the media version and start to treat them differently in negative ways: "They accepted it because the media said that's the way it is. To walk around with a feeling that everybody thinks you're an idiot or psychopath, obviously you will be influenced by it!"

In summary, the TV hosts' reports demonstrated a wide range of stressing factors in their relationship to the media. Negative media influenced them directly through encounters with journalists and news reports, and indirectly through interactions with people in their environment. Through the looking-glass process, they formed ideas about other peoples' attitudes towards them, based on the content of the media coverage and perceived changes in peers' and reference groups' behavior. This is in line with findings from other studies (Kepplinger \& Glaab, 2007, Karlsen \& Duckert, 2018).

Even if all the participants were upset and felt the he situation as unpleasant and stressful, the majority seemed to be only moderately influenced by the media related stress. However, two of the TV hosts reacted more strongly. Both of them described themselves as open and available to the press. They had expected the media to be respectful and decent in return, and were shocked and disappointed by the negative media exposure, and the way the journalists treated them.

\section{Coping strategies}

Our participants reported the use of a broad specter of coping strategies that involved both problem-solving and emotion-focused activities as described by Lazarus (2006). These varied from confronting journalists and editors, responding with their own versions of stories, blocking information, and withdrawal and isolation. Impression management and self-presentation seemed to be important for most of the TV hosts. In addition, they reported frequent use of meaning-focused strategies.

\section{Confronting media}

Half of the TV hosts reported that they had directly contacted the person(s) they considered as responsible for the critical press item, by email, telephone or direct meetings. They usually did this immediately, and often in anger: "I reacted violently to that picture, called the editor and wondered if this was a local newspaper worthy!"

Making direct contact could reduce the burden in several ways: This gave an opportunity for recognizion by important people in the case, and more influence than addressing a full press corps. Besides, they could direct their own frustration and anger directly towards the ones they perceived as responsible. Not least, this could discipline journalists: "If someone confronts the person who started the exposure, it is refusing to play the game. Then the journalist is forced down to a more realistic level."

However, this was a demanding strategy and could be risky: "It just made them more excited, so it was hopeless. It is not possible to clean yourself in newspaper ink. If someone prints things you do not like, just stay calm and move on."

\section{Impression management}

Typical of this group was their visibility in public. This did not change during the critical exposure. The program tasks were still there, and their audiences would continuously review them. Several mentioned explicitly that it was important to stay visible, in spite of the critics in the media.

One of the most senior TV hosts described how she, after a negative incident, made a conscious decision to wear high heels and lipstick and go to work. For her, it was important not to appear sad or weak, neither for the producers she worked for or for her viewers: "My viewers and the audience in the studio should not notice it. I'm not going to be one on TV where people think, "Poor one!" My job is actually to lead this program, not to be a victim of it - so I've done that. In any case, you should never show yourself weak to your crew, because they also think it's hard."

Important for impression management was the ability to mobilize available resources. For the majority of the participants, close colleagues had given the most important opportunities for distraction: "We are a close group that stays together. Had I been alone, I would have gone crazy. I'm coming to work and, "The hell, have you seen that post, it was terrible!" Then we'll work it a bit, and then we'll conclude - even though we know we're almost lying to each other: "Yes, but this is not so bad!' Sometimes I'm deeply aware that this is not good at all, but then, we convince ourselves." 
Several commented on the importance of competent, stable collegial friends. Such friends were familiar with the entertainment industry, the social games and the power struggles. They helped put things in perspective and could provide honest and relevant feedback. In addition, they could de-dramatize, correct and be confidential sparring partners. This was especially important when the media boiled.

Although several described that they had had to protect the family against the negative media exposure, most participants reported that they had received a lot of support, especially from partners: "They are at the same time both the main support and potential victims." Several emphasized the importance of close, confidential private relationships: "Having a good conversation is crucial. Knowing someone I can talk to about everything, without risking condemnation when I'm feeling low, and having a spouse who herself is a professional, and who realizes that this is part of the job - it's very important to me!"

\section{Self-presentation}

The majority of the TV hosts described strategic reflections on how their statements could be perceived and used by the press. Most were conscious of how to move the impressions of the journalists in a specific direction. The goal was to provide exciting information, without really exposing themselves. Self-disguising strategies and deliberate manipulation of their answers to protect themselves from the journalists' scrutiny were dominant in this group: "I do not respond to how I really feel but just how it should look. I do not give the newspaper a real feeling; I just give the press a strategy."

Being selective and strategic in relation to what kind of information they gave in interviews seemed to be appropriate in several ways. This gave more control over the use of their statements and the context in which they would appear. In addition, the journalists got something to work with which meant less speculation, less manufacturing of information and less use of quotes taken out of context. Such tactics also reduced the risk of giving the press something personally vulnerable: "The journalists and the media have given you a role, and you need to relate to it; work either with it or against it."

In our sample, the majority of those who experienced media exposure as a moderate and affordable burden reported to use active self-disguising strategies.

\section{Self-protecting strategies in public places}

One powerful aspect that many celebrities seem to face is an existential crisis in the interactions that fame brings them. From an initial desire to become successful, the celebrity experiences personal confusion and loss of ownership of life in a depersonalizing entitization process, in which they feel like a thing than rather a person of unique character. The public wants a piece of them, to touch them, to get an autograph, to have their picture taken in company with the star. All the while hearing one's name screamed out, the famous person feels as if she or he is not even there (Giles 2010). This also largely affected our TV hosts. They were public celebrities, and were easily recognized when they moved outside. Most experienced this as a burden, and all described different strategies for dealing with detections and contact from strangers.

The goal was to minimize contact with strangers to a minimum: "Have you heard of the 'tunnel vision'? Celebrity gaze? You avoid meeting peoples' eyes at all costs. You develop a tunnel vision for several reasons: One reason is that you become crazy seeing all who look at you, and you cannot stand looking back at them. You pretend that they do not look at you, because you are so self-conscious. Another is that with less eye contact, there is less risk of direct contact. Catching the look of someone opens up for conversation. Therefore, the celebrity vision is that you're just looking straight down or to the side but not on anyone."

A profiled female TV host reported: "I seem to be very attractive for odd and strange persons, very low threshold for anybody to contact me. However, I do not allow them to invade my life. I try to avoid going to the shops alone. If my husband or a friend is with me, the threshold becomes a bit higher."

The host of one of the most popular Friday night talk shows was very conscious about her role in public: "I try to back away from situations where I'm recognized or when someone will approach me in certain contexts. If I am at an opening night or something similar, and many know who I am, I look down and do not take over the room or anything like that. But if it's my opening night - and it's a red carpet, I'll offer the goodies. It's all about my own planning."

Some had long experience of celebrity status: "I've been doing this for 20 years. Before I thought it was terrible, but now I think I've chosen it voluntarily and most people are nice. I try to be nice too. Then I try to check whether people are drunk or fooling around. I adapt to this, saying; "Have a nice day!"

Another senior host described a repertoire of strategies, which kept minimizing the load: "I'm super nice, but taking charge immediately. Especially if I'm in motion, I will not stop. I'm just very 'so nice!' And touch them. I surprise them by being much nicer than they think. But also, to be damn fast, do you understand? I very quickly introduce them to someone else I am with - and then disappear. Very often, it's about people who are in the program or want to join. Then, very often I say; "You, know I'm very busy just now, but can you send me an email?" Such things." 


\section{Humor and playfulness}

An important feature of this group was the high incidence of humor and irony. This was also reflected in the way they handled the relationship with critical media. Half of the group described that they had found joy in fooling around with the press. Part of this was the support they received from significant others, and the excitement when they competed with the press in shaping their public images. They were also keen on finding humorous aspects in the interaction. The host of a satirical program reported: "Sometimes we responded straight and said, "No, this is not bad", sometimes we apologized, and sometimes we just did what we were supposed to do. Often, we just joked by saying; "I think she's saying this because she is actually lusting for me," or "This a kind of flirt, isn't it?" Responses like that, all sorts of variations."

Several stated that they also enjoyed counterattacking: "I tolerated it well and got new energy in my project. When I'm in such a warrior mode, I think it's fun!"

Conversations with colleagues and friends with media experience were often a crucial factor in finding humor and alternative perspectives. One of the female hosts reported: "The Chief Editor and I often delight in analyzing things in a gender perspective. Because it often follows a pattern. This type of girls gets this kind of critic, that kind of boys get that kind of critic. To me, men who are a bit lower than I am, often struggle: The Small Man Syndrome."

\section{Meaning focused strategies}

Almost all the TV hosts reflected that using a broader perspective lowered the intensity of their emotional responses, and made the case less dramatic and overwhelming: "I've been around so long and seen so much. I have worked with many people who have been great profiles and seen them being rolled down by scandals and rounds of media attention. The whole process includes how things are built up, come to a climax and then disappear, and who does really care about it?"

Several reflected that the media storms also could have positive aspects: "When you get engaged, it's because you think it's fun too. You get involved because you like a bit of storm. The press report that suggested I had false motives made an impact on me. However, I also enjoyed the reactions and the attention that followed."

The majority of the participants described that to obtain distance and alternative perspectives were important: "Media is media. We are all in a game and have roles in a soap opera. It's about making the best of it. You develop a certain pragmatism unlike the naivety you meet the media with when you are inexperienced."

The ability to see media coverage in a broader perspective was something that had evolved over time, through their own experiences and observations of others. Input from family, friends and colleagues also helped: "A colleague who had realized how stressing this was called me. I knew her a little, and she had been through something similar. She helped me get a different perspective, and made me realize that the whole world was not busy with me now."

Reactions from strangers could also be important: “Around the time I received critical media coverage, I traveled a lot. I met ordinary people, and realized how little it mattered! Critical media exposure seems big when it comes, but the effect is much less than one would think."

\section{Avoiding the press}

Half of the group stated that they had attempted to be unavailable to the press and had refused to comment. For some, it was because the situation became overwhelming: "I fled to my home place. Did not respond or go out. The newspapers came, and the phone rang all the time. I was horrified." For others, this was more about systematic cutting off access to information. Some, as principle, hardly ever responded to media criticism and considered these as ripples on the surface, with few lasting consequences.

Three expressed that they had needed time alone, away from the press, work and celebrities: "So, I did not go out of the door and cancelled all appointments - for two days." For one, this allowed him to calm down and regain focus. For the other two, this was more a flight away from the most intense attention. In addition, these two chose to extend their inaccessibility and boycotted the newspapers/ channels that provided the critical stuff.

A risk of choosing lonely withdrawal was that the situation could get worse and lead to a greater degree of brooding. None of the participants had used such a strategy systematically over time.

\section{Self-defensive strategies}

Three of the TV hosts described that they had communicated with the media in a more open and unreserved manner. They wanted to be heard and understood, and to be honest about their opinions. All three considered this as a part of their journalist mandate and expected to be met in a respectful and understanding manner by their outside colleagues. They seemed to have a strong link between inner experiences and outward appearance. However, such an intention of being honest and generous seemed to give an increased risk of stress: "I try to respond to all inquiries. When they turn 
to me, they'll get answers. I feel that I have some kind of loyalty to my journalist colleagues but end up feeling so frustrated and disappointed. Then a new thing comes up, and I think that this time it will be Ok, but no. The same thing happens time after time."

The stressful elements, which for all were frustrating, became particularly offensive when one had met the press with honest intentions. One of the participants reflected that being open and available for the press probably had made him more vulnerable to exploitation. To express oneself to the press in such a way could also imply that the press got a richer material, and that the exposure thus became more extensive, one became more personally involved and more receptive to further criticism. In addition, this increased the risk of being perceived as defensive.

Two of these three experienced strong negative after-reactions. However, the third had managed well through the media exposure and had a slightly different processing of the situation. He was less defensive and expressed that he throughout his career had participated in many debates and often represented unconventional positions: "I have participated in some debates over the years, such as the law on drugs, football and the Iraq war. Situations where I have raised my head, then someone would try to cut it off. That's the way it is. I take it easy. I rarely experience something as hurtful and offensive. I am knowledgeable and have good arguments. After all, I have an academic background. It has been annoying not to be taken seriously or to be ridiculed, but the stress has not been dominant. It has been fun too!"

\section{Discussion}

The ten TV-show hosts interviewed in our study were media experienced celebrities and well established in the Norwegian public. They experienced celebrity life as both good and bad, and their relationship with the media was intense and complex, characterized by mutual dependence, ambivalence and struggle for control. They were interesting targets for journalists, and needed the attention of the media in order to promote their TV programs.

Generally, all of these participants considered themselves as competent at handling media coverage. In the interviews, all reported to have been exposed to critical media coverage, which they had experienced as stressful personal attacks. This had made them angry, frustrated and involved, and they reacted to what they perceived as an unfair and erroneous representation of themselves in the media. They regarded the misrepresentation as caused by fraudulent journalism, characterized by subjective angulation, low trustworthiness and simplification of facts. Several had felt alone or betrayed by colleagues and management during the episode. The media exposure also influenced other parts of their life situation, by involving and harming family and friends.

The reciprocal media effects (Kepplinger, 2007) also affected the participants in our study, as they experienced stress directly related to the direct encounters with journalists and published press reports, but also indirectly through the reactions and behavior of family members, friends, and colleagues.

Our participants described problem-focused coping strategies, in which they made active attempts to influence the media coverage; emotion-focused coping strategies, aimed at regulating their thoughts and feelings; and meaning-focused strategies, which allowed space to reflect on the stressful media coverage and their own public role.

The TV celebrities demonstrated a high incidence of impression management. Furthermore, they used a wide repertoire of active coping strategies. They also used elaborate media strategies and often directly confronted journalists and editors. Some of the coping strategies, as playfulness, humor and fooling around with media, we have not seen mentioned in the literature or in previous empirical studies on stress and coping.

An earlier study has indicated that entertainers to a great degree use self-disclosure strategies (Schütz 1997). However, in our sample, self-disclosure was not used extensively. Only two of our informants reported self-disclosure as their main strategy towards the media. However, these two also reported more lasting personal damages. They described to have been overwhelmed by the press and felt more helplessness and despair during the exposure. They had spent more time alone withdrawing from the press, and avoided responding to the press demands. They also reported that they had used longer time before returning to normal.

As to coping strategies, in our study there seemed to be a difference between how the high-suffering and low-suffering participants dealt with the negative media exposure incidents. The high-sufferers seemed to have been using more defensive tactics in the interaction with media, and also more often withdrawing and isolating themselves. When speaking with the press, they seemed to be more self-disclosing and open.

The low-sufferers seemed to have been using more assertive and self-disguising strategies, confronting the critics, applying alternative perspectives, using humor and irony, and fooling around with the press. Such strategies can be categorized as assertive self-presentation (Lee \& al., 1998). Assertive self-presentation is meant to develop or create identities, whereas defensive tactics are used in order to defend or restore an identity, which has been spoiled.

An interesting finding in our study was that even though all participants reported misrepresentation and factual errors in 
the media as a source of burden, the majority had left out facts, expressed different opinions than they actually had, and in various other ways misrepresented themselves towards the media. Based on this, it may not be so much to be produced wrong that constituted the greatest strain, but rather not to control the production. Thus, the TV-hosts' misleading self-reports could be understood as a kind of pragmatic and effective management control in an industry where others wished to expose them to public curiosity and judgment

They were active in the negotiations with the outside world about their own identity and how they should be perceived (Leary and Allen 2011.) This can be regarded as a form of self-presentation work where their proactive strategies helped maintain and protect their individual identities.

\section{References}

Braun, V., \& Clarke, V. (2006). Using thematic analysis in psychology. Qualitative Research in Psychology, 3(2), 77-101. https://doi.org/10.1191/1478088706qp063oa

Buss, A. H., \& Briggs, S. R. (1984). Drama and the self in social intereaction. Journal of Personality and Social Psychology, 47, 1310-1324. https://doi.org/10.1037/0022-3514.47.6.1310

Giles, D. (2010). Psychology of the Media. Basingstoke, Hampshire: Palgrave Macmillan. https://doi.org/10.1007/978-1-137-05904-8

Hagen, A. L. (2015). Meningers mot- Netthat og ytringsfrihet i Norge. Oslo: Cappelen Damm akademisk.

Hill, C. E., \& Thompson, B. J. (1997). A guide to conducting consensual qualitative research. CounselingPsychologist, 25(4), 517-572. https://doi.org/10.1177/0011000097254001

Hill, C. E., Knox, S., Thompson, B. J., Williams, E. N., Hess, S. A., \& Ladany, N. (2005). Consensual Qualitative Research: An Update. Journal of Counseling Psychology, 52(2), 196-205. https://doi.org/10.1037/0022-0167.52.2.196

Karlsen, K. M., \& Duckert, F. (2018). Powerful and Powerless: Psychological Reactions of Norwegian Politicians Exposed in Media Scandals. International Journal of Communication, 12, 1-19.

Kepplinger, H. M. (2007). Reciprocal Effects: Toward a Theory of Mass Media Effects on Decision Makers. Press/Politics, 12(2), 3-23. https://doi.org/10.1177/1081180X07299798

Kepplinger, H. M., \& Glaab, S. (2007). Research note: Reciprocal effects of negative press reports. European Journal of Communication, 22(3), 337-354. https://doi.org/10.1177/0267323107079685

Lazarus, R. (2006). Stress and emotion: A new synthesis. New York: Springer

Leary, M. R., \& Allen, D. (2011). Personality and Persona: Personality Processes in Self-Presentation. Journal of Personality, 79(6), 1190-1218. https://doi.org/10.1111/j.1467-6494.2010.00704.x

Lee, S. J., Quigley, B. M., Nesler, M. S., Corbett, A. B., \& Tedeschi, J. T. (1998). Development of self-presentation tactic scale. Personality and Individual Differences, (26), 701-722. https://doi.org/10.1016/S0191-8869(98)00178-0

Redmond, S. (2014). Celebrity \& the Media. Hampshire: Palgrave MacMillan. https://doi.org/10.1007/978-1-137-38249-8

Rockwell, D., \& Giles, D. C. (2009). Being-in-the-world of celebrity: The phenomenology of fame. Journal of Phenomenological Psychology, 40, 178-210. https://doi.org/10.1163/004726609X12482630041889

Schlenker, B. R., \& Pontari, B. A. (2000). The strategic control of imformation: Impression management and self-presentation in daily life (pp. 199-232), in A.Tesser, R. B. Felson, \& J. M. Suls M (Eds.) Psychological Perspectives on Self and Identity. Washington: American Psychological Association. https://doi.org/10.1037/10357-008

Schütz, A. (1997). Self-Presentation Tactics of Talk-Show Guests: A Comparison of Politicans, Experts, and Entertainers. Journal of Applied Psychology, 27(21), 1941-1952.

https://doi.org/10.1111/j.1559-1816.1997.tb01633.x

\section{Copyrights}

Copyright for this article is retained by the author(s), with first publication rights granted to the journal.

This is an open-access article distributed under the terms and conditions of the Creative Commons Attribution license which permits unrestricted use, distribution, and reproduction in any medium, provided the original work is properly cited. 